\title{
Adubação verde na produção orgânica de alface americana e repolho ${ }^{1}$
}

\author{
Anastácia Fontanétti²; Gabriel José de Carvalho ${ }^{3}$; Luiz Antonio Augusto Gomes ${ }^{3}$; Karina de Almeida ${ }^{3}$; \\ Sylvia Raquel G de Moraes ${ }^{3}$; Cícero Monti Teixeira ${ }^{3}$ \\ ${ }^{2}$ UFV, Dep ${ }^{\text {to }}$. Fitotecnia, 36570-000 Viçosa-MG; ${ }^{3}$ UFLA, Dep ${ }^{\text {to }}$ Agricultura, C. Postal 37, 37200-000 Lavras-MG; E-mail: \\ afontanetti@yahoo.com.br; gab@ufla.com.br
}

\begin{abstract}
RESUMO
Na produção de hortaliças orgânicas a utilização exclusiva de composto orgânico tem se mostrado uma prática onerosa, em função do grande volume exigido para se obter produções comerciais. Uma das alternativas para a adubação complementar das hortaliças é a utilização da adubação verde. O objetivo deste trabalho foi avaliar três espécies de adubos verdes, utilizadas em complementação ao composto orgânico, quanto ao aporte de nutrientes ao solo, a produtividade e às características agronômicas de alface americana e repolho. O experimento foi instalado na Universidade Federal de Lavras, em Lavras-MG, no período de dezembro de 2001 a agosto de 2002. O solo foi classificado como LATOSSOLO VERMELHO Distrófico. O delineamento experimental foi o de blocos casualizados em esquema fatorial $4 \times 2$, com 3 repetições. Os fatores foram as leguminosas mucuna-preta (Stizolobium aterrimum), feijão-de-porco (Canavalia ensiformis.), e crotalária juncea (Crotalaria juncea.), mais uma testemunha (vegetação espontânea e adubação mineral); e as culturas de alface americana e repolho. A crotalária juncea apresentou o maior potencial de extração dos nutrientes $\mathrm{N}, \mathrm{P}, \mathrm{K}, \mathrm{Mg}, \mathrm{B}$, $\mathrm{Mn}$ e $\mathrm{Zn}$ do solo. Esta espécie foi ainda mais eficiente que o feijãode-porco e a mucuna-preta em aumentar o peso comercial de cabeça do repolho. Com relação à produção, para a alface os tratamentos de adubação verde mais composto orgânico não diferiram da testemunha; enquanto para repolho, tiveram um desempenho estatisticamente inferior. Entretanto, a utilização de adubo verde mais composto orgânico permitiu a obtenção de cabeças comerciais de alface americana e repolho com peso satisfatório para o mercado.
\end{abstract}

Palavras-chave: Brassica oleracea var. capitata $\mathrm{L}$, Lactuca sativa L., leguminosas.

\begin{abstract}
The use of green manure in crisphead lettuce and cabbage production
\end{abstract}

The exclusive use of organic compost in the production of organic vegetables has been found to be a costly practice due to the high volume of compost demanded to obtain commercial productions. Thus, one of the alternatives for complementary fertilization of vegetables is the use of green manure. The objective of this work was to evaluate three green manure species, used to complement the fertilization with organic compost, in relation to the nutrient contents in their biomass, and to productivity and agronomic traits of crisphead lettuce and cabbage. The experiment was carried out at the Olericulture Sector of the Federal University of Lavras (UFLA), in Lavras, Minas Gerais State, Brazil, from December 2001 to August 2002 , in a soil classified as Udox. The experiment was arranged in a randomized block design in a factorial scheme $(4 \times 2)$ with three repetitions. The first factor was constituted by the green manure species: black-velvet bean (Stizolobium aterrimum), jack bean (Canavalia ensiformis), and sunnhep (Crotalaria juncea), plus a control treatment (weed and mineral fertilizers); and the second factor was constituted by the vegetable crops: crisphead lettuce and cabbage. Among the tested green manure species, sunnhep presented the best potential for extraction of $\mathrm{N}, \mathrm{P}, \mathrm{K}, \mathrm{Mg}, \mathrm{B}, \mathrm{Mn}$ and $\mathrm{Zn}$. In addition, sunnhep was more efficient than jack bean or black velvet bean in increasing the commercial weight of cabbage head. In relation to productivity, as for lettuce, green manuring plus organic compost did not differ from the control; while for the cabbage, these treatments had a performance statistically inferior. The use of green manure plus organic compost allowed to obtain commercial crisphead lettuce and cabbage heads with satisfactory weight for the market.

Keywords: Brassica oleracea var. capitata L, Lactuca sativa L., leguminous, organic farming.

(Recebido para publicação em 5 de setembro de 2005; aceito em 28 de abril de 2006)

\begin{abstract}
$\mathrm{A}$ tualmente, a preocupação com o ambiente e a qualidade de vida tem difundido amplamente as correntes de agricultura alternativa, dentre elas, a agricultura orgânica. Esse sistema de produção tem crescido continuamente, em função de uma demanda cada vez maior por produtos orgânicos. O Brasil ocupa a $13^{\mathrm{a}}$ posição mundial quanto à área destinada à agricultura orgânica certificada, com mais de 275 mil hectares. Dentre os alimentos produzidos,
\end{abstract}

destacam-se as olerícolas para o mercado interno (Trivellato \& Freitas, 2003).

O repolho (Brassica oleracea var. capitata L.) e a alface (Lactuca sativa L.) estão incluídos entre as principais hortaliças de consumo diário do homem (Carneiro, 1981). Assim, para estas culturas existe grande potencial de mercado entre os produtos orgânicos, visto que essas são consumidas preferencialmente cruas, na forma de saladas, e apresentam elevado teor de vitaminas e de sais minerais, indispensáveis na dieta humana.

No Brasil, o plantio da alface tipo americana vem se destacando, principalmente, para atender às redes de "fast food" (Bueno, 1998). A sua aceitação no mercado in natura também tem se mostrado crescente, principalmente, por apresentar um maior período de conservação pós-colheita, quando comparada aos outros tipos de alface (Yuri, 2000). É considerada uma planta exigente 
nutricionalmente e, por essa razão, em sistema convencional, a maioria dos produtores utiliza o sistema de fertirrigação, com elevadas doses de adubos solúveis. Segundo Yuri (2000), no sul de Minas Gerais, a produção convencional alcança cerca de 500 toneladas por semana.

A alface geralmente apresenta boa resposta à adubação orgânica, no entanto, ela varia de acordo com a cultivar e a fonte de adubo utilizada. Ricci et al. (1995), estudando composto orgânico (tradicional) e vermicomposto na produção de alface, verificaram que a adubação com composto e vermicomposto proporcionou teores de $\mathrm{P}, \mathrm{Ca}, \mathrm{Mg}$ e $\mathrm{S}$ significativamente iguais à testemunha com adubação mineral.

Segundo Souza (1998), algumas espécies olerícolas são mais adaptadas ao sistema de produção orgânico como, por exemplo, o repolho. Esta hortaliça é a quinta mais produzida no Brasil, o que se deve a excelente composição nutricional, a versatilidade do consumo in natura e de processamento industrial e às propriedades terapêuticas, que fazem do repolho um alimento popular, barato e de grande importância sócio-econômica alimentar (Silva Junior, 1991). Por ser exigente em nitrogênio e em potássio, o repolho normalmente responde positivamente à adubação orgânica. Silva Junior (1991), estudando o efeito da aplicação de esterco curtido na produção convencional de repolho, concluiu que a utilização de $50 \mathrm{t} \mathrm{ha}^{-1}$ de esterco prescinde de suplementação mineral. A utilização exclusiva de composto orgânico e/ou de esterco animal para adubação das olerícolas, em sistema orgânico de produção, no entanto, tem se mostrado uma prática onerosa, em função do grande volume exigido para se obter produções comerciais. Além disso, a utilização desses insumos pode vir a ser limitada futuramente pela exigência da produção destes sob manejo orgânico. Segundo Altieri (2002), a simples substituição de insumos que agridem o ambiente, por outros menos agressivos, aumenta os custos de produção e não reduz a vulnerabilidade fundamental das monoculturas, o que não atende aos princípios fundamentais da produção orgânica de alimentos. A utilização de adubos verdes na adubação complementar das hortaliças é uma pratica que pode viabilizar o sistema de produção orgânico.

Entre os efeitos da adubação verde na fertilidade do solo estão o aumento do teor de matéria orgânica, a maior disponibilidade de nutrientes, a maior capacidade de troca de cátions efetiva, a diminuição dos teores de alumínio e a capacidade de reciclagem e mobilização de nutrientes (Calegari et al.,1993). Esses efeitos são bastante variáveis, dependendo da espécie utilizada, do manejo dado à biomassa, da época de plantio e de corte do adubo verde, do tempo de permanência dos resíduos no solo, das condições locais e da interação entre esse fatores (Alcântara et al., 2000).

Entre os adubos verdes promissores para a prática da adubação verde destacam-se a mucuna-preta (Stizolobium aterrimum Piper \& Tracy.), a crotalária juncea (Crotalaria juncea L.) e o feijão-de-porco (Canavalia ensiformis DC.), por serem plantas rústicas, de eficiente desenvolvimento vegetativo, adaptadas a condições de baixa fertilidade e elevadas temperaturas (Pereira et al., 1992). Assim, o objetivo deste trabalho foi avaliar essas três espécies de adubo verde quanto ao aporte de nutrientes ao solo e a adubação complementar das hortaliças, seus efeitos na produtividade e em algumas características agronômicas da alface americana e do repolho.

\section{MATERIAL E MÉTODOS}

O experimento foi conduzido de dezembro/01 a agosto/02, na UFLA em Lavras (MG). O solo da área experimental foi classificado como LATOSSOLO VERMELHO Distrófico de textura argilosa. Sua caracterização química (camada de $0-10 \mathrm{~cm}$ ) revelou os seguintes resultados: $\mathrm{pH}$ em água 5,8; 10,8 $\mathrm{mg} \mathrm{dm}^{-3}$ de P; $186 \mathrm{mg} \mathrm{dm}^{-3} \mathrm{de} \mathrm{K} ; 2,7 \mathrm{cmol}_{\mathrm{c}} \mathrm{dm}^{-3}$ de $\mathrm{Ca} ; 0,3 \mathrm{cmol}_{\mathrm{c}} \mathrm{dm}^{-3} \mathrm{de} \mathrm{Mg} ; 0,1 \mathrm{cmol}_{\mathrm{c}}$ $\mathrm{dm}^{-3}$ de $\mathrm{Al} ; 3,2 \mathrm{cmol}_{\mathrm{c}} \mathrm{dm}^{-3} \mathrm{de} \mathrm{H}+\mathrm{Al} ; 3,5$ $\mathrm{cmol}_{\mathrm{c}} \mathrm{dm}^{-3} \mathrm{de}$ soma de bases (SB); 3,6 $\mathrm{cmol}_{\mathrm{c}} \mathrm{dm}^{-3}$ de CTC efetiva; $6,7 \mathrm{cmol}_{\mathrm{c}} \mathrm{dm}^{-3}$ de CTC potencial; $51,9 \%$ de saturação por bases (V) e 2,9 dag $\mathrm{kg}^{-1}$ de matéria orgânica; $\mathrm{pH}$ em água (na proporção de 1: 2,5 para solo: água); $\mathrm{Ca}, \mathrm{Mg}$ e $\mathrm{Al}$ (extrator $\mathrm{KCl} 1 \mathrm{~N}$ ); $\mathrm{P}$ e $\mathrm{K}$ (extrator
Mehlich 1) e acidez extraível (H+Al) (extrator SMP). O C orgânico foi determinado pelo método colorimétrico (Quaggio \& Raij, 1979) e a porcentagem de matéria orgânica estimada, multiplicando-se o teor de C orgânico por 1,724 .

O delineamento experimental adotado foi o de blocos casualizados em esquema fatorial $4 \times 2$ com 3 repetições. $\mathrm{O}$ primeiro fator foi constituído pelas leguminosas: mucuna-preta (Stizolobium aterrimum Piper \& Tracy.), feijão-deporco (Canavalia ensiformis DC.), crotalária juncea (Crotalaria juncea L.) e por uma testemunha (vegetação espontânea) e o segundo, pelas culturas de alface americana cultivar Raider e repolho cultivar Kenzan. A parcela experimental teve a dimensão de $4 \times 3 \mathrm{~m}$.

O preparo do solo foi feito no sistema convencional, com aração e gradagem e posterior semeadura da mucuna-preta e do feijão-de-porco, com espaçamento de $0,50 \mathrm{~m}$ entre linhas e $0,20 \mathrm{~m}$ entre plantas, e $0,50 \mathrm{~m}$ entre linhas e $0,05 \mathrm{~m}$ entre plantas para a crotalária juncea. As parcelas da testemunha não foram capinadas até o plantio das hortaliças.

As mudas das hortaliças foram produzidas em casa de vegetação coberta com plástico e laterais fechadas com tela clarite. A semeadura foi feita em bandejas de isopor de 128 células contendo o substrato comercial Plantmax ${ }^{\circledR}$.

As leguminosas foram roçadas com uma roçadeira costal e incorporadas ao solo com auxílio de uma grade de disco, em março de 2002. Um mês após a incorporação, os canteiros para o plantio da alface americana foram preparados manualmente. Não foi realizada, em nenhum tratamento, a calagem do solo. As hortaliças foram transplantadas no início de maio de 2002, sendo a alface americana no espaçamento de $0,5 \times 0,3$ $\mathrm{m}$ e o repolho em covas com espaçamento de $0,6 \times 0,4 \mathrm{~m}$. Foram consideradas para as avaliações duas linhas úteis para a alface americana e três para o repolho.

Na testemunha, utilizou-se adubação mineral baseada na análise de solo e de acordo com a recomendação da Comissão de Fertilidade do Solo do Estado de Minas Gerais (1999): para a alface ame- 
Tabela 1. Produção de massa verde (MV), matéria seca (MS) e teor de matéria seca (MS) das plantas de cobertura. UFLA, Lavras, 2002.

\begin{tabular}{|c|c|c|c|}
\hline \multirow{2}{*}{ Plantas de cobertura } & MV & MS & \multirow{2}{*}{ MS ( $\%)$} \\
\hline & \multicolumn{2}{|c|}{$\left(t_{\text {ha }}^{-1}\right)$} & \\
\hline Crotalária juncea & $39,33 a^{1}$ & $12,75 \mathrm{a}$ & 29,8 a \\
\hline Mucuna-preta & 42,43 a & $8,50 \mathrm{~b}$ & $20,1 b$ \\
\hline Feijão-de-porco & 35,86 a & $7,51 \mathrm{bc}$ & $22,3 b$ \\
\hline Vegetação espontânea & $22,75 \mathrm{~b}$ & $5,24 \mathrm{c}$ & $24,6 \mathrm{~b}$ \\
\hline $\mathrm{CV}(\%)$ & 14,95 & 21,87 & 11,67 \\
\hline
\end{tabular}

${ }^{1}$ Médias seguidas das mesmas letras nas colunas não diferem significativamente entre si pelo teste de Tukey a $5 \%$ de probabilidade.

ricana utilizaram-se $400 \mathrm{~kg} \mathrm{ha}^{-1} \mathrm{P}_{2} \mathrm{O}_{5}$, $150 \mathrm{~kg} \mathrm{ha}^{-1}$ de $\mathrm{K}_{2} \mathrm{O}$ e $150 \mathrm{~kg} \mathrm{ha}^{-1}$ de $\mathrm{N}$, sendo o último parcelado em $75 \mathrm{~kg} \mathrm{ha}^{-1}$ no plantio, $50 \mathrm{~kg} \mathrm{ha}^{-1}$ aos 30 dias após o plantio e $25 \mathrm{~kg} \mathrm{ha}^{-1}$ aos 45 dias após o plantio; para o repolho utilizaram-se 100 $\mathrm{kg} \mathrm{ha}^{-1} \mathrm{P}_{2} \mathrm{O}_{5}, 100 \mathrm{~kg} \mathrm{ha}^{-1}$ de $\mathrm{K}_{2} \mathrm{O}$ e 150 $\mathrm{kg} \mathrm{ha}^{-1}$ de $\mathrm{N}$, sendo o último parcelado em $30 \mathrm{~kg} \mathrm{ha}^{-1}$ no plantio e aos 30 dias após o plantio e $45 \mathrm{~kg} \mathrm{ha}^{-1}$ aplicados aos 45 e 65 dias após o plantio; também se aplicou $1 \mathrm{~g}$ de ácido bórico por cova. Nas parcelas com as leguminosas utilizouse a adubação com composto orgânico na dosagem de $20 \mathrm{t} \mathrm{ha}^{-1}$ (peso úmido), em duas aplicações: $10 \mathrm{t} \mathrm{ha}^{-1}$ no plantio e $10 \mathrm{t} \mathrm{ha}^{-1} 30$ dias após o plantio, para ambas hortaliças. Os resultados da análise química do composto orgânico, com base no peso seco, foram: $16,60 \mathrm{~g} \mathrm{~kg}^{-1}$ de N; 4,19 $\mathrm{g} \mathrm{kg}^{-1}$ de P; 2,62 $\mathrm{g} \mathrm{kg}^{-1}$ de K ; 9,56 $\mathrm{g} \mathrm{kg}^{-1}$ de $\mathrm{Ca} ; 3,68 \mathrm{~g} \mathrm{~kg}^{-1}$ de $\mathrm{Mg}$; $2,11 \mathrm{~g} \mathrm{~kg}^{-1}$ de $\mathrm{S} ; 10,75 \mathrm{mg} \mathrm{kg}^{-1}$ de B; $35,62 \mathrm{mg} \mathrm{kg}^{-1} \mathrm{de} \mathrm{Cu} ; 37242,60 \mathrm{mg} \mathrm{kg}^{-1}$ de Fe; 274,73 $\mathrm{mg} \mathrm{kg}^{-1} \mathrm{de}$ Mn e 71,90 mg $\mathrm{kg}^{-1}$ de $\mathrm{Zn}$, determinados de acordo com a metodologia descrita por Kiehl (1985); e umidade $13 \%$.

Avaliou-se a parte aérea da vegetação espontânea e das leguminosas, no início do florescimento, coletando-se amostras de $1 \mathrm{~m}^{2}$ por parcela. As amostras foram pesadas, para obtenção da massa fresca, sendo retirados $500 \mathrm{~g}$ de cada material para determinação de matéria seca e concentração de nutrientes, devolvendo-se o restante à área experimental. O material recolhido foi levado até estufa com ventilação forçada de ar à temperatura de $65^{\circ} \mathrm{C}$ por um período de cinco dias (até estabilização do peso). Em seguida, o material foi novamente pesado para a obtenção do teor de matéria seca e a matéria seca total (teor de matéria seca x peso fresco)/100. Avaliou-se a concentração de nutrientes nas leguminosas e na vegetação espontânea, determinando-se os teores de $\mathrm{N}, \mathrm{P}, \mathrm{K}, \mathrm{Ca}, \mathrm{Mg}, \mathrm{S}, \mathrm{B}, \mathrm{Cu}, \mathrm{Fe}, \mathrm{Mn}, \mathrm{e} \mathrm{Zn}$, segundo Malavolta et al. (1989). As quantidades acumuladas de nutrientes foram obtidas através da quantidade de matéria seca e da concentração dos nutrientes das leguminosas e da vegetação espontânea, em cada amostra. Para cada tratamento, os valores médios da quantidade acumulada de macronutrientes foram transformados em $\mathrm{kg} \mathrm{ha}^{-1} \mathrm{e}$ os de micronutrientes, em $\mathrm{g} \mathrm{ha}^{-1}$.

As colheitas da alface americana e respectivamente. As plantas foram cortadas logo abaixo das folhas basais, bem rentes ao solo. Para a determinação da massa fresca total da alface americana, as plantas foram pesadas em balança com sensibilidade de cinco gramas. Em seguida, retiraram-se as folhas externas obtendo-se o peso comercial da "cabeça". A circunferência da "cabeça" comercial foi medida utilizando-se uma fita métrica conforme recomenda Yuri (2000).

Para o repolho foram avaliados o peso comercial de cabeça, em gramas, retirando-se as folhas externas e pesando-se a cabeça. A altura foi medida da base (inserção das folhas no caule) ao ápice da cabeça, utilizando-se uma régua plástica. Já para o diâmetro horizontal, foi feito um corte no centro da cabeça no sentido horizontal e esse foi medido com auxílio de uma fita métrica.

Os valores das características avaliadas foram submetidos a análises de variância, utilizando-se o programa estatístico SISVAR (Ferreira, 2000) e as médias foram comparadas pelo teste de do repolho ocorreram aos 65 e 90 dias
Tukey a 5\% de probabilidade.

\section{RESULTADOS E DISCUSSÃO}

Para as coberturas vegetais (leguminosas e vegetação espontânea), verificou-se diferença significativa para as variáveis massa verde, matéria seca e teor de matéria seca. A vegetação espontânea produziu menor quantidade de massa verde e de matéria seca, enquanto que as leguminosas não diferiram entre si na produção de massa verde. No entanto, a crotalária juncea apresentou maior produção e teor de matéria seca em relação a mucuna-preta e ao feijãode-porco (Tabela 1).

De modo geral, a produtividade das leguminosas superou os limites propostos por Calegari (1995): de 10 a $40 \mathrm{t} \mathrm{ha}^{-1}$ e de 14 a $30 \mathrm{t} \mathrm{ha}^{-1}$ massa verde para mucuna-preta e feijão-de-porco, respectivamente. Já para a crotalária juncea, a produtividade de $39,33 \mathrm{t} \mathrm{ha}^{-1}$ foi inferior a mencionada por Alvarenga et al. (1995), que foi de 52,3 $\mathrm{t} \mathrm{ha}^{-1}$ de massa verde com plantio em novembro, fato talvez relacionado à sensibilidade dessa leguminosa ao fotoperíodo. A crotalária juncea é uma espécie de dias curtos e o plantio em dezembro pode ter diminuído sua produção de massa verde, por favorecer o florescimento.

O teor de matéria seca da mucunapreta e do feijão-de-porco foi equivalente ao obtido por Oliveira et al. (2002). Para a crotalária juncea, a produtividade de matéria seca foi menor que a citada por Alvarenga et al. (1995), de 16,1 t ha ${ }^{-1}$, e maior que a obtida por Alcântara et al. (2000), de 6,5 $\mathrm{t} \mathrm{ha}^{-1}$.

Para a quantidade acumulada e incorporada ao solo de macro e de micronutrientes pelas plantas de cobertura, verificou-se diferença significativa para todos os nutrientes analisados. O maior acúmulo de nitrogênio ocorreu na crotalária juncea, seguido por mucunapreta e feijão-de-porco e o menor, na vegetação espontânea (Tabela 2). Esses dados são semelhantes aos resultados obtidos por Alvarenga et al. (1995), que verificaram os maiores acúmulos de nitrogênio na crotalária juncea $\left(252,9 \mathrm{~kg} \mathrm{ha}^{-1}\right)$, mucuna-preta $\left(191,5 \mathrm{~kg} \mathrm{ha}^{-1}\right)$ e no feijão-de-porco $\left(146,2 \mathrm{~kg} \mathrm{ha}^{-1}\right)$. Também os maiores acúmulos de $\mathrm{P}, \mathrm{K}$ e Mg fo- 
Tabela 2. Acúmulo de macro e de micronutrientes nas plantas de cobertura, por ocasião do corte e incorporação das palhadas ao solo. UFLA, Lavras, 2002.

\begin{tabular}{|c|c|c|c|c|c|c|c|c|c|c|c|}
\hline \multirow{2}{*}{ Plantas de cobertura } & $\mathbf{N}$ & $\mathbf{P}$ & $\mathbf{K}$ & $\mathrm{Ca}$ & $\mathrm{Mg}$ & $\mathbf{S}$ & B & $\mathrm{Cu}$ & Mn & $\mathrm{Zn}$ & $\mathrm{Fe}$ \\
\hline & \multicolumn{6}{|c|}{$\left(\mathrm{kg} \mathrm{ha}^{-1}\right)$} & \multicolumn{5}{|c|}{$\left(\mathrm{g} \mathrm{ha}^{-1}\right)$} \\
\hline Crotalária juncea & $374,85 a^{1}$ & $42,07 a$ & $195,71 \mathrm{a}$ & $159,16 a$ & $33,15 a$ & $33,57 b$ & $369 a$ & $116 b$ & $717 \mathrm{a}$ & 403 a & $3163 a b$ \\
\hline Feijão-de-porco & $246,95 b$ & $22,40 \mathrm{c}$ & $121,91 \mathrm{c}$ & $196,14 a$ & $17,27 b$ & $44,84 a$ & $291 b$ & $49 c$ & $431 b$ & $140 \mathrm{c}$ & $1451 b$ \\
\hline Vegetação espontânea & $67,68 \mathrm{c}$ & $17,03 c$ & $105,59 c$ & $35,46 b$ & $14,23 b$ & $16,68 d$ & $88 \mathrm{c}$ & $47 \mathrm{c}$ & $405 \mathrm{~b}$ & $187 \mathrm{c}$ & 4183 a \\
\hline $\mathrm{CV}(\%)$ & 18,71 & 16,15 & 12,05 & 20,70 & 21,05 & 13,89 & 12,04 & 16,20 & 18,50 & 16,40 & 25,08 \\
\hline
\end{tabular}

${ }^{1}$ Médias seguidas das mesmas letras nas colunas não diferem significativamente entre si pelo teste de Tukey a 5\% de probabilidade.

ram observados na crotalária juncea, enquanto que para o $\mathrm{S}$ os maiores acúmulos foram encontrados no feijãode-porco. Com relação ao $\mathrm{Ca}$, os maiores acúmulos foram encontrados na crotalaria juncea e no feijão-de-porco.

Quanto aos micronutrientes, observou-se que a crotalária juncea acumulou em sua biomassa maiores quantidades de B, Mn e Zn, enquanto que o maior acúmulo de $\mathrm{Cu}$ ocorreu na mucuna-preta. Já para o $\mathrm{Fe}$, encontrou-se os maiores acúmulos na vegetação espontânea, na crotalária juncea e na mucuna-preta, enquanto o menor acúmulo ocorreu na biomassa do feijão-de-porco (Tabela 2).

A capacidade das plantas de cobertura estudadas, de absorverem nutrientes e imobilizá-los, seguiu a mesma tendência no que se refere à produção de matéria seca. Nesse caso, a crotalária juncea foi à espécie mais eficiente tanto na produção de matéria seca quanto na absorção e acúmulo da maioria dos nutrientes. Já a vegetação espontânea teve a menor produção de matéria seca e os menores acúmulos de nutrientes, a exceção do Fe. No entanto, vale ressaltar que embora uma espécie de adubo verde imobilize grande quantidade de nutrientes em sua biomassa, isso não significa que esses nutrientes estarão prontamente disponíveis à cultura subseqüente (Alvarenga et al.,1995).

Para a alface americana não houve diferença significativa para nenhuma das características agronômica estudadas (Tabela 3), o que mostra a viabilidade do uso desses adubos verdes utilizados como complementação à adubação orgânica, na substituição à adubação mineral, na produção dessa hortaliça. Mesmo no tratamento com feijão-de-porco, que dentre as leguminosas foi a que apresentou menor acúmulo de nutrientes, a exceção do
Ca e S, verificou-se uma média de produção de massa fresca da alface superior a mencionada por Rodrigues \& Casali (1999), que aplicando $37,7 \mathrm{tha}^{-1} \mathrm{de}$ composto orgânico obtiveram a média de 119,5 $\mathrm{g}$ planta $^{-1}$ de alface cultivar Babá de Verão, o que pode indicar um ganho de produtividade com a adubação complementar advinda da incorporação das leguminosas. No entanto, Yuri (2000) e Yuri et al. (2002), para a cultivar Raider, na mesma época de plantio, obtiveram a média de 996,27 g de massa fresca por planta, diferindo dos resultados obtidos nesse experimento, inclusive pela testemunha. Este fato provavelmente está relacionado ao tipo de manejo efetuado por estes autores, utilização de plástico para a cobertura dos canteiros e, também, pelo uso de irrigação por gotejamento e fertirrigação.

De acordo com Yuri et al. (2004) a dose de 59,4 tha ${ }^{-1}$ de composto orgânico com suplementação de nitrogênio e potássio via fertirrigação foi a que proporcionou a máxima produtividade da alface americana 914,2 g planta ${ }^{-1}$. A maior produtividade da alface quando se utiliza dose elevada de composto orgânico pode ser atribuída ao fato de que parte do nitrogênio presente em adubos orgânicos resiste à rápida mineralização (Smith \& Hadley, 1989). Quando se cultivam espécies de ciclo curto como a alface, o aumento da dose do composto orgânico pode garantir maior produtividade. Segundo Santos et al. (2001), a adubação orgânica possui um efeito residual que pode acarretar em aumento de produção às culturas subseqüentes. Dessa forma, espera-se um aumento na produtividade da alface americana nos próximos ciclos.

Para o repolho, verifica-se que as cabeças comerciais produzidas em área que teve a vegetação espontânea como planta de cobertura e receberam a adubação mineral, apresentaram a maior massa fresca comercial, diâmetro e altura das cabeças. Entre as leguminosas, não se observou diferença significativa para os parâmetros avaliados (Tabela 3).

A absorção dos nutrientes, advindos da mineralização dos adubos verdes, pelas hortaliças depende em grande parte, da sincronia entre a decomposição e mineralização dos resíduos vegetais e a época de maior exigência nutricional da cultura. De acordo com Diniz (2004), 24 dias após a incorporação dos resíduos de mucuna cinza (Stizolobium cinereum), $50 \%$ do nitrogênio presente no adubo verde já havia sido liberado. A maior taxa de absorção e acúmulo de nutrientes do repolho ocorre entre $60 \mathrm{e}$ 70 dias após o transplante. Assim, possivelmente, não houve sincronia entre a máxima liberação de nutrientes dos adubos verdes e a época de maior exigência nutricional do repolho, pois o transplante das mudas ocorreu aproximadamente 40 dias após a incorporação das leguminosas. No entanto, o tratamento com pré-plantio de crotalária juncea apresentou massa fresca comercial e diâmetro da cabeça sem diferenças significativas em relação ao tratamento com vegetação espontânea e adubação mineral, provavelmente por essa leguminosa ter apresentado o maior acumulo de matéria seca e de nutrientes.

Comparando-se as médias de peso comercial apresentadas pelo repolho nos tratamentos com as leguminosas mais composto orgânico, verifica-se que essas em geral foram maiores que as $900 \mathrm{~g}$, mencionadas por Oliveira et al. (2001), em ensaios utilizando $41,0 \mathrm{t}^{-1}$ de esterco bovino em solo com $1,13 \%$ de matéria orgânica e semelhantes aos re- 
Tabela 3. Produção de massa fresca total (MF total), massa fresca comercial (MF com.) e circunferência (Circunf.) da cabeça de alface americana e massa fresca comercial, diâmetro (Diâm.) e altura (Alt.) da cabeça de repolho em função das plantas de cobertura. UFLA, Lavras, 2002.

\begin{tabular}{|c|c|c|c|c|c|c|}
\hline \multirow{3}{*}{ Plantas de cobertura } & \multicolumn{3}{|c|}{ Alface americana } & \multicolumn{3}{|c|}{ Repolho } \\
\hline & \multirow{2}{*}{$\begin{array}{r}\text { MF total } \\
(\mathrm{g}\end{array}$} & \multirow{2}{*}{ MF com. } & \multirow{2}{*}{$\begin{array}{c}\text { Circunf. } \\
(\mathrm{cm})\end{array}$} & \multirow{2}{*}{$\begin{array}{l}\text { MF com. } \\
\text { (g) }\end{array}$} & Diâm. & Alt \\
\hline & & & & & \multicolumn{2}{|c|}{$(\mathrm{cm})$} \\
\hline Crotalária juncea & $332,7 a^{1}$ & $280,0 \mathrm{a}$ & $38,0 \mathrm{a}$ & $1378,0 a b$ & $15,6 a b$ & $9,6 \mathrm{~b}$ \\
\hline Mucuna-preta & 409,0 a & 356,0 a & $38,7 \mathrm{a}$ & $1215,3 \mathrm{~b}$ & $15,3 a b$ & $9,3 b$ \\
\hline Feijão-de-porco & 294,0 a & $236,0 \mathrm{a}$ & 37,0 a & $1238,3 \mathrm{~b}$ & $15,0 \mathrm{~b}$ & 9,3 \\
\hline Vegetação espontânea & 487,7 a & 415,0 a & $40,3 a$ & $1960,0 \mathrm{a}$ & $19,3 \mathrm{a}$ & $13,0 \mathrm{a}$ \\
\hline $\mathrm{CV}(\%)$ & 18,07 & 19,77 & 4,22 & 15,92 & 9,13 & 9,54 \\
\hline
\end{tabular}

${ }^{1}$ Médias seguidas das mesmas letras nas colunas não diferem significativamente entre si pelo teste de Tukey a 5\% de probabilidade.

sultados encontrados por Oliveira et al. (2005), que em áreas com pré-cultivo de crotalária, obtiveram médias de $1260 \mathrm{~g}$ de massa fresca comercial e diâmetro horizontal de $15,87 \mathrm{~cm}$ de cabeças de repolho, atingindo os padrões do mercado consumidor brasileiro, que é de 1000 a $1500 \mathrm{~g}$ de massa fresca comercial (Lêdo et al., 2000).

Pelo exposto anteriormente, concluise que, dentre os adubos verdes estudados, a crotalária juncea apresentou a maior produção de matéria seca e os maiores acúmulos dos nutrientes $\mathrm{N}, \mathrm{P}$, $\mathrm{K}, \mathrm{Mg}, \mathrm{B}, \mathrm{Mn}$ e $\mathrm{Zn}$, sendo, portanto, a espécie mais promissora para o aporte de nutrientes ao solo, advindo da decomposição/mineralização da biomassa.

A utilização dos adubos verdes como complemento ao composto orgânico, mesmo no primeiro ano de cultivo orgânico, o qual representa um sistema em início de conversão, permitiu a obtenção de cabeças comerciais de alface americana e de repolho com peso satisfatório para o mercado, demonstrando que a adubação verde pode ser considerada uma prática promissora na produção dessas hortaliças em sistema orgânico.

\section{AGRADECIMENTOS}

Ao CNPq, pela concessão de bolsa a primeira autora.

\section{REFERÊNCIAS}

ALCÂNTARA FA; NETO AEF; PAULA MB; MESQUITA HA; MUNIZ JA. 2000. Adubação verde na recuperação da fertilidade de um Latossolo Vermelho-Escuro degradado. Pesquisa Agropecuária Brasileira 35: 277-288.
ALTIERI M. 2002. Agroecologia: Bases científicas para uma agricultura sustentável. Guaíba: Agropecuária. 592p.

ALVARENGA RC; COSTA LM; MOURA FILHO W; REGAZZI AJ. 1995. Características de alguns adubos verdes de interesse para a conservação e recuperação de solos. Pesquisa Agropecuária Brasileira 30: 175-185.

BUENO RC. 1998. Adubação nitrogenada em cobertura via fertirrigação por gotejamento para a alface americana em ambiente protegido. Lavras: UFLA. 54p. (Dissertação mestrado).

CALEGARI A; MONDARDO A; BULISANI EA; COSTA MBB; MIYASAKA S; AMADO TJC. 1993. Aspectos gerais da adubação verde. In: COSTA MBB (Coord). Adubação verde no sul do Brasil. 2. ed. Rio de Janeiro: Assessoria e Serviços a Projetos em Agricultura Alternativa. p.1-56. ra do repolho (Brassica oleracea var capitata L.) e a cultura da alface (Lactuca sativa L.) de população. Piracicaba: USP/ESALQ. 69p. (Dissertação mestrado).

COMISSÃO DE FERTILIDADE DO SOLO DO ESTADO DE MINAS GERAIS. 1999. Recomendações para o uso de corretivos e fertilizantes em Minas Gerais: $5^{\text {a }}$ aproximação. Viçosa. $359 \mathrm{p}$.

DINIZ ER. 2004. Influência da época de incorporação de adubo verde na produção de brócolis cultivado organicamente. Viçosa: UFV. 63p. (Dissertação mestrado).

FERREIRA DF. 2000. Análise estatísticas por meio do SISVAR para Windows versão 4.0. In: REUNIÃO BRASILEIRA DA SOCIEDADE INTERNACIONAL DE BIOMETRIA, 45. Programas e Resumos... São Carlos: UFScar. p. 235, 2000.

KIEHL EJ. 1985. Fertilizantes orgânicos. Piracicaba: Agronômica Ceres. 492p.

LÊDO FJS; SOUZA JA; SILVA MR. 2000. Avaliação de cultivares e híbridos de repolho no Estado do Acre. Horticultura Brasileira 18: 138-140.

MALAVOLTA E; VITTI GC; OLIVEIRA AS. 1989. Avaliação do estado nutricional de plantas, princípios e aplicações. Piracicaba: POTAFOS. 210p.
CARNEIRO IF. 1981. Competição entre a cultuem cultivo misto e em diferentes densidades
OLIVEIRA AP; FERREIRA DS; COSTA CC; SILVA AF; ALVES EU. 2001. Uso de esterco bovino e húmus de minhoca na produção de repolho híbrido. Horticultura Brasileira 19: 70-73.

OLIVEIRA TK; CARVALHO GJ; MORAES RNS. 2002. Plantas de cobertura e seus efeitos sobre o feijoeiro em plantio direto. Pesquisa Agropecuária Brasileira 37: 1079-1087.

OLIVEIRA FL; RIBAS RGT;JUNQUEIRA RM; PADOVAM MP; GUERRA JGM; ALMEIDA DL; RIBEIRO RLD. 2005. Desempenho do consórcio entre repolho e rabanete com précultivo de crotalaria, sob manejo orgânico. Horticultura Brasileira 23: 184-188.

PEREIRA J; BURLE ML; RESCK DVS. 1992. Adubos verdes e sua utilização no cerrado. In SIMPÓSIO SOBRE MANEJO E CONSERVAÇÃO DO SOLO NO CERRADO, 1990, Goiânia, GO. Anais... Campinas: Fundação Cargil. p. 140-154.

QUAGGIO JA; RAIJ B. 1979. Comparação de métodos rápidos para a determinação da matéria orgânica em solos. Revista Brasileira de Ciência do Solo 3: 184-187.

RICCI MSF; CASALI VW; CARDOSO AA; RUIZ HA. 1995. Teores de nutrientes em duas cultivares de alface adubadas com composto orgânico. Pesquisa Agropecuária Brasileira 30: 1035-1039.

RODRIGUES ET; CASALI VWD. 1999. Rendimento e concentração de nutrientes em alface, em função das adubações orgânica e mineral. Horticultura Brasileira 17: 125-128.

SANTOS RHS; SILVAF; CASALI VWD; CONDES AR. 2001. Efeito residual da adubação com composto orgânico sobre o crescimento e produção de alface. Pesquisa Agropecuária Brasileira 36: 1395-1398.

SILVA JUNIOR AA. 1991. Efeitos da adubação mineral e orgânica em repolho. Agropecuária Catarinense 4: 53-56.

SMITH SR; HADLEYP. 1989. A comparison of organic and inorganic nitrogen fertilizers: their nitrate- $\mathrm{N}$ and ammonium-N release characteristics and effects and growth response of lettuce (Lactuca sativa L. cv. Fortune). Plant and Soil 115: 135-144.

SOUZA JL. 1998. Agricultura Orgânica. Vitória: EMCAPA. 176p.

TRIVELLATO MD; FREITAS GB. 2003. Panorama da Agricultura Orgânica. In STRINGUETA PC; MUNIZ JN. Alimentos orgânicos: Produção tecnologia e certificação. Viçosa: UFV. p. 9-35.

YURI JE. 2000. Avaliação de cultivares de alface americana em duas épocas de plantio em dois locais do Sul de Minas Gerais. Lavras: UFLA. 51p. (Dissertação mestrado).

YURI JE; SOUZA RJ; FREITAS SAC; RODRIGUES JC; MOTA JH. 2002. Comportamento de cultivares de alface tipo americana em Boa Esperança. Horticultura Brasileira 20: 229-232.

YURI JE; RESENDE GM; RODRIGUES JÚNIOR JC; MOTA JH; SOUZA RJ. 2004 Efeito de composto orgânico sobre a produção e características comerciais de alface americana. Horticultura Brasileira 22: 127-130. 